\title{
Performances of CPAP Devices With an Oronasal Mask
}

\author{
Maria Vargas MD, Annachiara Marra PhD, Luigi Vivona MD, Lorenzo Ball MD, \\ Valeria Marinò MD, Paolo Pelosi MD, and Giuseppe Servillo MD
}

\begin{abstract}
BACKGROUND: The aim of this bench study was to investigate the performances of 8 devices for noninvasive CPAP. METHODS: Eight devices for noninvasive CPAP with an orofacial mask were studied: Ventumask, Ventumask 30, EasyVent, EasyVent Emergency, Compact Model II, Flowone, Superflow, Boussignac CPAP valve. Each device was tested at oxygen input flows from 5 to 20 $\mathrm{L} / \mathrm{min}$, and the output gas flow was measured in static conditions. Each device was evaluated during a eupneic and a tachypneic simulated breathing test. RESULTS: The gas output flow generated by each device increased with higher oxygen input flow; EasyVent and Flowone produced the highest output flow $(P<.001)$. At the simulated eupneic breathing test, Superflow and EasyVent showed a more stable pressure swing at different PEEP levels, whereas the other masks had a greater swing, between 10 and $15 \mathrm{~cm} \mathrm{H}_{2} \mathrm{O}$ PEEP ( $P=.002$ for all pairwise comparisons). During the tachypneic breathing test, the pressure swing was stable with Flowone and EasyVent $(P=.055)$, whereas it had increased with other masks ( $P=.002$ for all pairwise comparisons). CONCLUSIONS: We found a significant variation in the performances of the 8 CPAP devices examined in this study. The technical characteristics and limitations of different CPAP devices should be considered when using in patients with hypoxemic acute respiratory failure. Key words: CPAP; mechanical ventilation; respiratory failure; hypoxemia; orofacial mask; effectiveness; efficacy. [Respir Care 2018;63(8):1033-1039. ( 2018 Daedalus Enterprises]
\end{abstract}

\section{Introduction}

Noninvasive CPAP is a widely used ventilation technique to improve oxygenation. ${ }^{1,2}$ CPAP devices provide a specific level of positive pressure during the respiratory cycle to prevent alveolar collapse and increase lung volume. ${ }^{3}$ Recently, several devices for short-term use have been made available; these are capable of delivering CPAP at different pressure levels while only requiring a gas source

\footnotetext{
Dr Vargas, Ms Marra, Mr Vivona, and Dr Servillo are affiliated with Department of Neurosciences, Reproductive and Odontostomatological Sciences, University of Naples, Federico II, Naples, Italy. Drs Ball and Pelosi are affiliated with Department of Surgical Sciences and Integrated Diagnostics, San Martino Policlinico Hospital, Istituto di Ricovero e Cura a Carattere Scientifico for Oncology, University of Genoa, Genoa, Italy. Ms Marinò is affiliated with Department of Anesthesia and Intensive Care, Istituto di Ricovero e Cura a Carattere Scientifico Istituto Neurologico Mediterraneo, Neuromed, Pozzilli, Italy.
}

Dr Servillo discloses a relationship with Deas. The other authors have disclosed no conflicts of interest.

Supplementary material related to this paper is available at http:// www.rcjournal.com. to be operated. These devices are ideal for use in settings such as extra-hospital or intra-hospital emergencies, which allows positive-pressure respiratory assistance in patients who are not intubated. ${ }^{4}$ The level of CPAP is determined in most devices by an adjustable or fixed PEEP valve, and the total gas flow is essential to ensure a stable pressure level throughout the respiratory cycle, ${ }^{3}$ with a minimum flow of $60 \mathrm{~L} / \mathrm{min}$ generally required in patients with an increased respiratory demand. ${ }^{4}$ This study compared 8 devices for noninvasive CPAP with an orofacial mask. Seven devices used the Venturi effect to generate flow: Ventumask (Starmed, Mirandola, Italy), Ventumask 30 (Starmed), EasyVent (Dimar, Mirandola, Italy), EasyVent Emergency (Dimar), Compact Model II (Harol, San Donato Milanese, Italy); Flowone (Deas, Castelbolognese, Italy), and Superflow

\footnotetext{
Correspondence: Maria Vargas MD, Department of Neurosciences, Reproductive and Odontostomatological Sciences, Section of Anaesthesia and Intensive Care, University of Naples, Federico II, Via S Pansini 5, Naples, Italy 80131. E-mail: vargas.maria82@gmail.com.
}

DOI: $10.4187 /$ respcare. 05930 
(Deas). One device, the Boussignac CPAP valve (Vygon, Ecouen, France), used the Bernoulli principle with a virtual valve effect. ${ }^{3}$

The aim of this study was to investigate the performances of these 8 CPAP devices in terms of effectiveness, defined as evaluation of output flow generation in static conditions, and of efficacy, defined as airway pressure swing, namely the difference between inspiratory and expiratory pressures during simulated spontaneous breathing with eupneic and tachypneic respiratory patterns. We hypothesized that the effectiveness and efficacy were different in the tested devices. The work was performed at the University of Naples Federico II, Naples, Italy.

\section{Methods}

\section{Devices}

Eight devices for noninvasive CPAP with orofacial mask were studied (Fig. 1): Ventumask, Ventumask 30, EasyVent, EasyVent Emergency, Compact Model II, Flowone, Superflow, and Boussignac CPAP valve. These devices operate with a single external oxygen source, and some also have an additional oxygen source, located downstream from the air-entrainment valve, that may be used to increase $\mathrm{F}_{\mathrm{IO}_{2}}$. The characteristics of the masks evaluated in the present study are shown in Table 1. The Boussignac CPAP valve system is the only commercially available device that does not incorporate an air-entrainment Venturi system: this device consists of a small cylinder that, when receiving the oxygen, the flow generates a turbulence, which thus acts as a virtual PEEP valve and results in a positive airway pressure. All other CPAP systems use the Venturi effect to entrain room air and generate a high output flow, and an adjustable or calibrated mechanical PEEP valve is used to set the desired positive pressure level.

\section{Experimental Setting}

Output Flow Generation. An oxygen source was connected to the devices and a flow meter, which measures the air flow generated by the CPAP device, was positioned downstream from the air-entrainment valve. A rapid response oxygen analyzer $\left(\mathrm{MaxO}_{2}+\mathrm{AE}\right.$; Maxtec, Salt Lake City, Utah) was placed at the side port of the devices to evaluate the delivered $\mathrm{F}_{\mathrm{IO}_{2}}$. Each device was tested at increasingly higher oxygen source flows, from $5 \mathrm{~L} / \mathrm{min}$ up to $20 \mathrm{~L} / \mathrm{min}$ in 4 steps. The primary outcome was the output-flow generation (effectiveness) of the different CPAP devices; the secondary outcome was the airway inspiratory-expiratory pressure swing (efficacy) during simulated spontaneous eupneic and tachypneic respiratory patterns. Pressure swing $(\Delta \mathrm{p})$ was defined as the difference between inspiratory and expiratory airway

\section{QUICK LOOK}

\section{Current knowledge}

Noninvasive CPAP is the most commonly used ventilation technique in prehospital and emergency settings; its benefits in patients with hypoxemic acute respiratory failure are well known.

\section{What this paper contributes to our knowledge}

The results of the static and dynamic tests performed indicated that the Dimar and Deas devices showed the best performance in terms of output flow generation and pressure swing around the imposed PEEP level compared with the Starmed, Harol, and Boussignac CPAP devices. The characteristics and the limitations of different CPAP devices should be considered when used in patients with hypoxemic acute respiratory failure.

pressure around the CPAP level and was considered as an indicator of the work of breathing. ${ }^{2}$

Static Test. Each mask was evaluated at 4 increasing levels of PEEP $\left(5,10,15\right.$, and $\left.20 \mathrm{~cm} \mathrm{H}_{2} \mathrm{O}\right)$ obtained with adjustable valves and a pressure manometer that measured the actual pressure inside the device. Each device was evaluated for generated output flow with a flow meter analyzer (Fluke Biomedical, Cleveland, Ohio), $\mathrm{F}_{\mathrm{IO}_{2}}$ and with pressure that started from $5 \mathrm{~L} / \mathrm{min}$ of oxygen to $20 \mathrm{~L} / \mathrm{min}$, according to the recommendations of the manufacturer.

Simulated Breathing Test. Each device was evaluated during simulated spontaneous breathing by using a lung model (Deas). Each mask was connected to a pneumatic lung simulator with a preset respiratory frequency, volume and inspiratory-expiratory ratio while generating a sinusoidal flow. A pressure transducer, $\mathrm{F}_{\mathrm{IO}_{2}}$ analyzer, and flow analyzer were serially connected. Two breathing patterns were investigated: (1) eupneic breathing with a volume of $500 \mathrm{~mL}$, rate of $20 \mathrm{breaths} / \mathrm{min}$, minute volume of $10 \mathrm{~L} / \mathrm{min}$, and inspiratory-expiratory ratio $1: 2$; (2) tachypneic breathing with volume size of $800 \mathrm{~mL}$, rate of 30 breaths/min, minute volume of $24 \mathrm{~L} / \mathrm{min}$, and inspiratory-expiratory ratio $1: 1$. Each device was tested for 2 min of uninterrupted simulated breathing.

\section{Statistical Analysis}

Data were reported as mean $\pm \mathrm{SD}$. All data were analyzed by averaging 3 replicates from each experiment. Normality was assessed with the D'Agostino-Pearson omnibus test. The total gas flow generated by different devices was compared with a 2-way analysis of variance. 


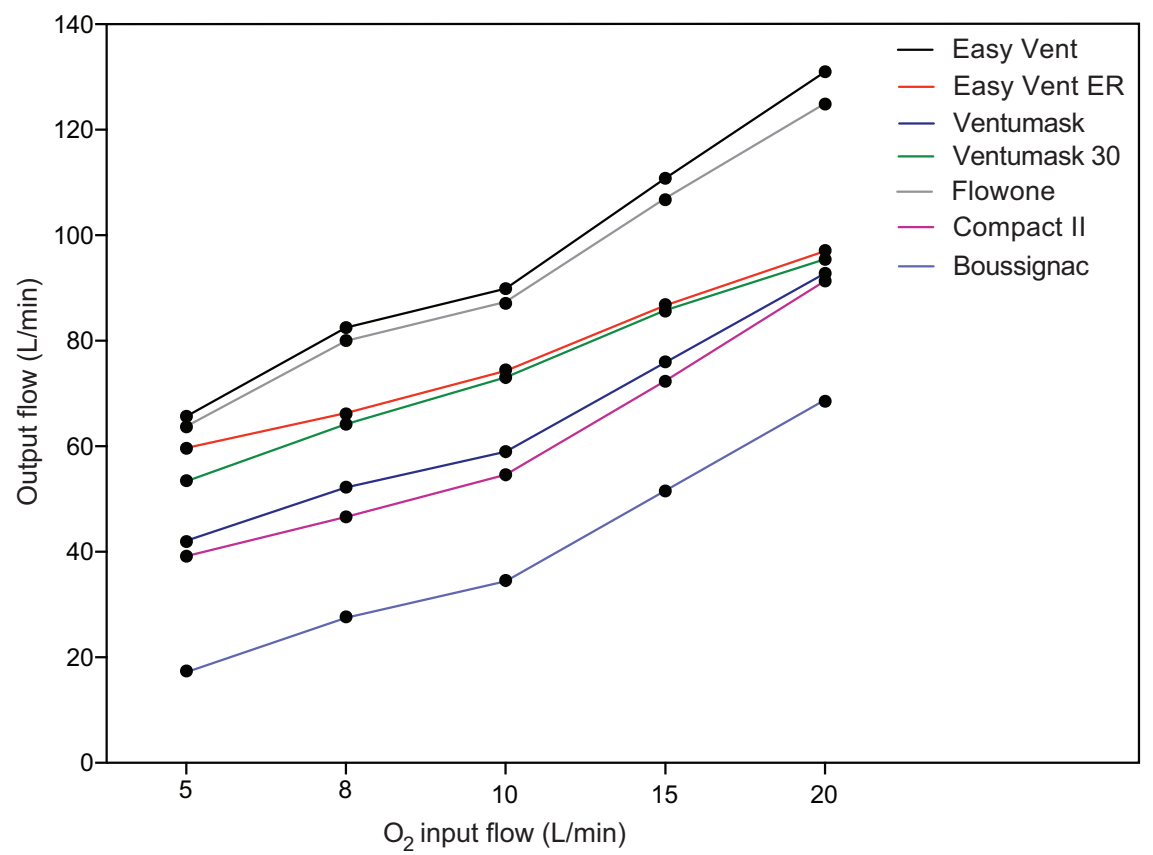

Fig. 1. Output flow generated by each device according the $\mathrm{O}_{2}$ input flow.

Table 1. Characteristics of Different CPAP Devices Included in the Study

\begin{tabular}{|c|c|c|c|c|c|c|}
\hline Device & $\begin{array}{l}\text { Venturi } \\
\text { Device }\end{array}$ & $\begin{array}{l}\text { Concentration } \\
\text { of } \mathrm{O}_{2}(\%)^{*}\end{array}$ & $\begin{array}{c}\text { Feed With } \\
\text { Flow A + Flow B }\end{array}$ & $\begin{array}{c}\text { Maximum Flow } \\
\text { Delivered (L/min) } \dagger\end{array}$ & $\begin{array}{l}\text { Adjustable } \\
\text { PEEP Valve }\end{array}$ & $\begin{array}{c}\text { PEEP } \\
\text { Level }\left(\mathrm{cm} \mathrm{H}_{2} \mathrm{O}\right)\end{array}$ \\
\hline Easy Vent & + & $33-100$ & + & 120 & + & $5,10,15,20$ \\
\hline Easy Vent Emergency & + & 33 & - (only flow A) & 120 & + & $5,10,15,20$ \\
\hline Ventumask & + & $\begin{array}{l}40,50,60,100 \text { (with a } \\
\text { minimum } \mathrm{O}_{2} \text { flow of } \\
42 \mathrm{~L} / \mathrm{min} \text { ) }\end{array}$ & + & 60 & + & $5,7.5,10,12.5$ \\
\hline Ventumask 30 & + & $\begin{array}{l}30,40,50,60,100 \text { (with } \\
\text { a minimum } \mathrm{O}_{2} \text { flow of } \\
40 \mathrm{~L} / \mathrm{min} \text { ) }\end{array}$ & + & 80 & + & $5,7.5,10,12.5,15,20$ \\
\hline Flowone & + & 30 & + & 122 & - & \\
\hline Superflow & + & $30-60$ & + & $122 \mathrm{~L} / \mathrm{min}$ & + & $5,10,15,20$ \\
\hline Compact Model II & + & $40-70$ & + & $77 \mathrm{~L} / \mathrm{min}$ & + & $5,10,15$ \\
\hline Boussignac & - & $30,50,100$ & - & NA & - & $\begin{array}{r}2,4,5,7,10 \text { (according } \\
\text { to the delivered flow) }\end{array}$ \\
\hline $\begin{array}{l}{ }_{*}^{*} \text { Concentration of } \mathrm{O}_{2} \text { approxi } \\
\dagger \text { As declared by the manufact } \\
\mathrm{NA}=\text { not applicable } \\
+=\text { present } \\
-=\text { absent } \\
\text { Flow } \mathrm{A}=\text { Main flow } \\
\text { Flow } \mathrm{B}=\text { Adjunctive flow }\end{array}$ & $\begin{array}{l}\text { tely reached. } \\
\text { er. }\end{array}$ & & & & & \\
\hline
\end{tabular}

The relationship between the oxygen input flow and generated air-flow output of each device was investigated with a linear regression analysis. Pressures obtained at the static and dynamic tests were compared by using the KruskalWallis test with Dunn post hoc analysis. All statistical analyses were performed by using SPSS version 21 (IBM, Armonk, New York), and significant at $P<.05$.

\section{Results}

\section{Output Flow Generation}

The gas output flow generated by each device increased with higher $\mathrm{O}_{2}$ flow input (Fig. 1). The results of the linear regression are reported in Table 2. The Dimar EasyVent 
Table 2. Output Flow Generation Performance of Each Tested Device

\begin{tabular}{lccc}
\hline \hline \multicolumn{1}{c}{ Device } & Slope $(95 \% \mathrm{CI})$ & Intercept & $\mathrm{r}^{2}$ \\
\hline Easy Vent & $0.219-0.238$ & -10.4 & 0.99 \\
Ventumask & $0.292-0.306$ & -7.6 & 0.99 \\
Ventumask 30 & $0.334-0.418$ & -16.3 & 0.98 \\
Flowone & $0.231-0.259$ & -11.1 & 0.99 \\
Superflow & $0.331-0.456$ & -9.4 & 0.98 \\
Easy Vent Emergency & $0.357-0.435$ & -19 & 0.98 \\
Compact Model II & $0.27-0.3$ & -5.6 & 0.99 \\
Boussignac & $0.287-0.293$ & 0.008 & 1
\end{tabular}

Results are from the linear regression of the output flow generated vs the input flow.

and Deas Flowone produced the greatest output flow at each $\mathrm{O}_{2}$ input flow compared with the other devices (Dimar Easy Vent output flow generation 5, 10, 15, and $20 \mathrm{~L} / \mathrm{min}$ input flow: 65.6, 8.71, 90.6, 110.9, and 132.1 L/min. Deas Flowone output flow generation $5,10,15$, and $20 \mathrm{~L} / \mathrm{min}$ input flow: 63.7, 80.5, 86.4, 107.1, and $125.7 \mathrm{~L} / \mathrm{min}$ ).

\section{Static Test}

The masks evaluated at 4 levels of PEEP $(5,10,15$, and $20 \mathrm{~cm} \mathrm{H}_{2} \mathrm{O}$ ) with oxygen input flow of $20 \mathrm{~L} / \mathrm{min}$ are shown in Figure 2. At $20 \mathrm{~L} / \mathrm{min}$, the Dimar EasyVent and Deas Flowone generated the highest output flow at each PEEP level (output flows at each PEEP level of Dimar EasyVent vs Deas Flowone, $P=.99$ ), even if Deas Flowone output flow decreased at $40 \mathrm{~L} / \mathrm{min}$ with $20 \mathrm{~cm} \mathrm{H}_{2} \mathrm{O}$ of PEEP level. The Deas Flowone had the highest increase of $\mathrm{F}_{\mathrm{IO}_{2}}$ at 15 and $20 \mathrm{~cm} \mathrm{H} \mathrm{H}_{2} \mathrm{O}$ of PEEP $\left(\mathrm{F}_{\mathrm{IO}_{2}}, 39.3 \%\right.$ and $55 \%$, respectively). The performances of all the masks evaluated at 4 levels of PEEP $\left(5,10,15\right.$, and $\left.20 \mathrm{~cm} \mathrm{H}_{2} \mathrm{O}\right)$ with oxygen source flows of 10 and $30 \mathrm{~L} / \mathrm{min}$ are shown in the supplementary materials (see http://www.rcjournal.com).

\section{Simulated Breathing Test}

The airway pressure swing $(\Delta p)$ during simulation of eupneic and tachypneic breathing patterns is shown in Figure 3. During the eupneic breathing pattern test, the Deas Superflow and Dimar EasyVent showed a more stable $\Delta \mathrm{p}$ at different PEEP levels (Deas Superflow $\Delta \mathrm{p}: 2.38,2.98$, and $4.33 \mathrm{~cm} \mathrm{H}_{2} \mathrm{O}$; and Dimar EasyVent $\Delta \mathrm{p}: 2.80,3.03$, 4.03, and $3.68 \mathrm{~cm} \mathrm{H}_{2} \mathrm{O}$ at 5, 10, 15 and $20 \mathrm{~cm} \mathrm{H}_{2} \mathrm{O}$ PEEP, respectively), whereas the other masks had a greater swing between 10 and $15 \mathrm{~cm} \mathrm{H}_{2} \mathrm{O}$ of PEEP (Dimar EasyVent Emergency $\Delta$ p: 9.9 and $7.3 \mathrm{~cm} \mathrm{H}_{2} \mathrm{O}$; Starmed Ventumask $\Delta$ p: 6.6 and $4.3 \mathrm{~cm} \mathrm{H}_{2} \mathrm{O}$; Starmed Ventumask $30 \Delta$ p: 3.9 and $6.1 \mathrm{~cm} \mathrm{H}_{2} \mathrm{O}$; Deas Flowone $\Delta \mathrm{p}: 4.3$ and $2.9 \mathrm{~cm} \mathrm{H}_{2} \mathrm{O}$; Harol Compact Model II $\Delta$ p: 6.3 and $7 \mathrm{~cm} \mathrm{H}_{2} \mathrm{O}$; Vygon
Boussignac $\Delta \mathrm{p}: 0.8$ and $1.1 \mathrm{~cm} \mathrm{H}_{2} \mathrm{O}$ at $5,10,15$, and $20 \mathrm{~cm} \mathrm{H}_{2} \mathrm{O}$ PEEP, respectively) $(P=.002$ for all pairwise comparisons).

With the tachypneic breathing pattern test, $\Delta \mathrm{p}$ was stable between the Deas Flowone and Dimar EasyVent (Deas Flowone $\Delta \mathrm{p}: 13.7,14.8,14.7$, and $16.6 \mathrm{~cm} \mathrm{H}_{2} \mathrm{O}$; and Dimar EasyVent $\Delta \mathrm{p}: 6.3,7.1,7.9$, and $10.8 \mathrm{~cm} \mathrm{H}_{2} \mathrm{O}$ at 5, 10, 15 , and $20 \mathrm{~cm} \mathrm{H}_{2} \mathrm{O}$ PEEP, respectively) $(P=.055$ for all pairwise comparisons), whereas $\Delta \mathrm{p}$ increased with other masks ( $P<.001$ for all pairwise comparisons). The inspiratory and expiratory pressures during eupneic and tachypneic breathing pattern simulations are shown in the supplementary materials (see http://www.rcjournal.com). During the eupneic breathing pattern test, Flowone had the highest inspiratory pressure than the other devices (Deas Flowone inspiratory pressure: $3.3,7.2,11.4$, and $13.9 \mathrm{~cm}$ $\mathrm{H}_{2} \mathrm{O}$ at 5, 10, 15, and $20 \mathrm{~cm} \mathrm{H}_{2} \mathrm{O}$ PEEP, respectively) $(P<.001$ for all paired comparison), whereas, with tachypnea breathing, the Deas Flowone and Dimar EasyVent Emergency had the highest inspiratory pressure Deas Flowone inspiratory pressure: $1.1,5.5,9.2$, and $14.7 \mathrm{~cm}$ $\mathrm{H}_{2} \mathrm{O}$; and Dimar EasyVent Emergency inspiratory pressure: $12.4,15.5,16.8$, and $16.6 \mathrm{~cm} \mathrm{H}_{2} \mathrm{O}$ at $5,10,15$, and $20 \mathrm{~cm}$ $\mathrm{H}_{2} \mathrm{O}$ PEEP, respectively) $(P<.001$ for all paired comparison). The expiratory pressures were not different during both breathing pattern simulations.

\section{Discussion}

\section{Main Findings}

In this bench study, we found that (1) the capability to deliver an adequate output flow was different among the CPAP devices, and (2) the devices showed different performances in eupneic and tachypneic simulated breathing conditions. CPAP devices are compact and easy-to-use systems $^{5}$ that have been shown to delay or avoid intubation in acute respiratory failure due to cardiac and noncardiac conditions, in both prehospital and hospital settings. ${ }^{5,6}$ A recent meta-analysis that included 8 randomized trials showed that the prehospital use of CPAP reduced mortality and the risk for intubation compared with standard care, whereas the effectiveness of prehospital bi-level inspiratory positive airway pressure was uncertain. ${ }^{7,8}$

From this perspective, CPAP may play a major role for the treatment of acute respiratory failure. ${ }^{4,7}$ Because different CPAP devices have recently been marketed, it is important for the medical staff to know the individual performance of different brands, and thus identify the best tools to be applied in specific populations of patients. The strength of our study was that, to our knowledge, this was the first bench comparison of the effectiveness and efficacy of 8 different CPAP devices, including the Boussignac system. The Boussignac system is the most studied 

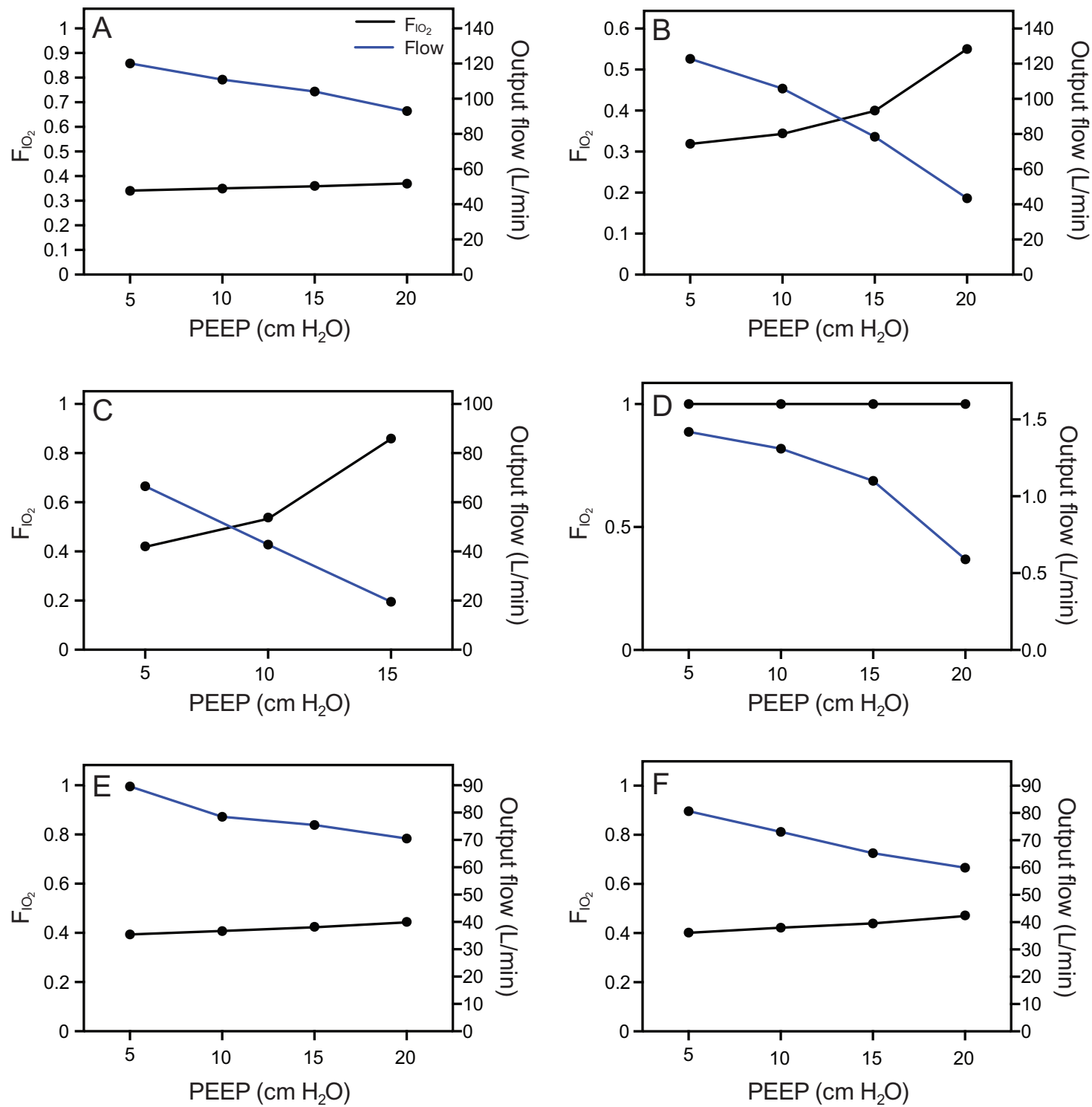

Fig. 2. Static test for each device performed with 4 levels of PEEP $\left(5,10,15\right.$, and $\left.20 \mathrm{~cm} \mathrm{H}_{2} \mathrm{O}\right)$ with oxygen source flows of $20 \mathrm{~L} / \mathrm{min}$. (A) Easy Vent. (B) Flowone. (C) Compact II. (D) Boussignac. (E) Ventumask 30. (F) Ventumask.

CPAP device. ${ }^{3}$ There is limited literature that compares different devices based on the Venturi system. One study compared 3 CPAP masks, ${ }^{9}$ whereas our study evaluated 8 devices.

In the present study, the efficiency of the devices was compared based on oxygen flow needed to generate a minimum air flow of $60 \mathrm{~L} / \mathrm{min}$ at each CPAP setting, generally required in patients with an increased respiratory demand. ${ }^{4,8}$ In this study, the Dimar EasyVent and Deas Flowone generated an output flow of $60 \mathrm{~L} / \mathrm{min}$ with $5 \mathrm{~L} / \mathrm{min}$ of $\mathrm{O}_{2}$ input flow and an output flow of $120 \mathrm{~L} / \mathrm{min}$ with $20 \mathrm{~L} / \mathrm{min}$ of input flow. Probably because of the different experimental setting, these results are slightly different from those reported by Brusasco et al ${ }^{9}$ in which the Dimar EasyVent generated an output flow of $<60 \mathrm{~L} / \mathrm{min}$ with $5 \mathrm{~L} / \mathrm{min}$ of $\mathrm{O}_{2}$ input flow.

The static test aimed to evaluate the performances of the devices in developing adequate output flow by using the Venturi system; the generated flow linearly decreased, whereas $\mathrm{F}_{\mathrm{IO}_{2}}$ increased at higher PEEP. ${ }^{10}$ According to Brusasco et $\mathrm{al}^{9}$, at increased PEEP levels, from 5 to $20 \mathrm{~cm}$ $\mathrm{H}_{2} \mathrm{O}$ at $15 \mathrm{~L} / \mathrm{min}$ of $\mathrm{O}_{2}$ input flow, the $\mathrm{O}_{2}$ output flow of the Starmed devices dramatically decreased, and $\mathrm{F}_{\mathrm{IO}_{2}}$ increased up to $45 \%$, whereas the Dimar EasyVent mask kept a stable $\mathrm{F}_{\mathrm{IO}_{2}}$ of $40 \%$, with a decreasing $\mathrm{O}_{2}$ output flow. ${ }^{9}$

The devices were tested with $10,20,30 \mathrm{~L} / \mathrm{min}$ of $\mathrm{O}_{2}$ input flow and CPAP levels from 5 to $20 \mathrm{~cm} \mathrm{H}_{2} \mathrm{O}$. Inter- 

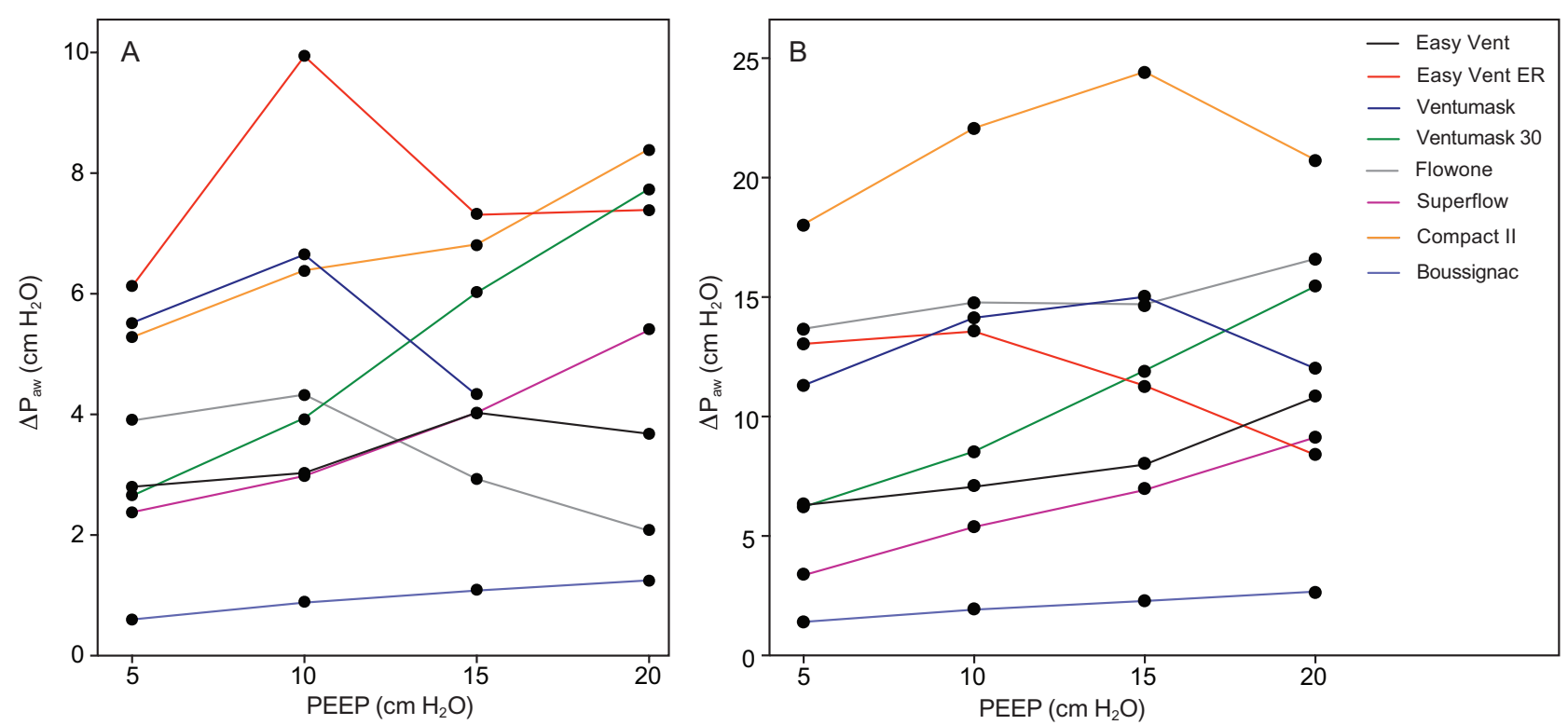

Fig. 3. The change in airway pressure $\left(\Delta P_{\text {aw }}\right)$ during the eupneic breathing $(A)$ and tachypneic breathing $(B)$.

estingly, at $10 \mathrm{~L} / \mathrm{min}$ of $\mathrm{O}_{2}$ input flow, we found that all devices, except the Boussignac system, markedly decreased the output flow, from 60 to $20 \mathrm{~L} / \mathrm{min}$. At $20 \mathrm{~L} / \mathrm{min}$, only the Dimar devices and the Starmed Ventumask kept the $\mathrm{O}_{2}$ output flow of $>60 \mathrm{~L} / \mathrm{min}$ for all PEEP, whereas the Deas Flowone kept the $\mathrm{O}_{2}$ output flow at $>60 \mathrm{~L} / \mathrm{min}$ only with PEEP of $<15 \mathrm{~cm} \mathrm{H}_{2} \mathrm{O}$.

\section{Clinical Implications}

A good CPAP device should maintain constant positive pressure during the respiratory cycle to be able to reduce the work of breathing. ${ }^{10}$ The respiratory muscles activity during CPAP results in fluctuations in the airway pressure around the imposed PEEP level, therefore, a greater pressure swing is associated with increased respiratory effort. ${ }^{11}$ Moreover, the additional work of breathing may induce respiratory muscle fatigue and discomfort in patients with acute respiratory failure. ${ }^{12}$ With regard to these premises, the majority of devices included in this study may not adequately assist patients because these devices showed a huge fluctuation of the airway pressures around the imposed PEEP level. During the eupneic and tachypneic breathing pattern simulations, the Dimar Easyvent, Deas Flowone, and Superflow showed the lowest pressure swing around the imposed PEEP level, which suggested a better ability to reduce the work of breathing. However, these results should be confirmed in clinical studies.

CPAP devices are mainly used in patients with acute respiratory failure and respiratory distress. The inspiratory pressure of the CPAP devices, according to our results in physiologic breathing simulation, was always above zero. Even during the stressful breathing test, 3 devices (Harol Compact Model II, Starmed Ventumask, and Boussignac) showed an inspiratory pressure of less than zero. A positive pressure maintained during the inspiratory phase may decrease the inspiratory effort and, thus, the work of breathing in patients with acute respiratory failure. ${ }^{13}$

\section{Limitations}

Our findings should be interpreted in the context of several limitations. First, this was an in vitro study, thus clinical studies are needed to confirm our results. Second, during breath simulation, we chose only 2 breathing patterns, which did not reproduce the broad spectrum of clinical conditions that can affect patients. Third, Starmed and Harol masks are now available in North America, Australia, and New Zealand, whereas Dimar and Deas masks were only recently introduced in the market. Fourth, the Deas Superflow, with the same characteristics of Deas Flowone but with the addition of a PEEP valve, was evaluated only in the breathing simulation tests.

\section{Conclusions}

As a result of the static and dynamic tests performed, we found a relevant variation in the effectiveness and efficacy of the 8 CPAP devices included in this study. The Dimar and Deas devices showed the best performance in terms of output flow generation and pressure swing around the imposed PEEP level compared with Starmed, Harol, and Bous- 


\section{CPAP Performance With Oronasal Mask}

signac CPAP devices. The characteristics and limitations of different CPAP devices should be considered when used in patients with acute respiratory failure.

\section{REFERENCES}

1. Kosowsky JM, Stephanides SL, Branson RD, Sayre MR. Prehospital use of continuous positive airway pressure (CPAP) for presumed pulmonary edema: a preliminary case series. Prehosp Emerg Care 2001;5(2):190-196.

2. Foti G, Sangalli F, Berra L, Sironi S, Cazzaniga M, Rossi GP, et al. Is helmet CPAP first line pre-hospital treatment of presumed severe acute pulmonary edema? Intensive Care Med 2009;35(4):656-662.

3. Wong DT, Tam AD, Van Zudert TC. The usage of the Boussignac continuous positive airway pressure system in acute respiratory failure. Minerva Anestesiol 2013;79(5):564-570.

4. Baudouin S, Blumenthal S, Cooper B, Davidson C, Davidoson A, Elliot M, et al. British Thoracic Society Standards of Care Committee. Non-invasive ventilation in acute respiratory failure. Thorax 2002;57(3):192-211.

5. Spijker EE, de Bont M, Bax M, Sandel M. Practical use, effects and complications of prehospital treatment of acute cardiogenic pulmonary edema using the Boussignac CPAP system. Int J Emerg Med 2013;6(1):1-8.
6. Williams TA, Perkins GD, Jacobs JG. Prehospital continuous positive airway pressure for acute respiratory failure: a systematic review and meta-analysis. Prehosp Emerg Care 2013;17(2):261-273.

7. Goodacre S, Stevens JW, Pandor A, Poku E, Ren S, Cantrell A, et al. Prehospital noninvasive ventilation for acute respiratory failure: systematic reviewed, network meta-analysis, and individual patient data meta-analysis. Acad Emerg Med 2014;21(9):960 970.

8. Salturk C, Esquinas AM. CPAP devices for emergency prehospital use: looking inside of it. Respir Care 2016;61(5):719.

9. Brusasco C, Corradi F, De Ferrari A, Ball L, Kacmarek RM, Pelosi P. CPAP device for emergency prehospital use: a bench study. Respir Care 2015;60(12):1777-1785.

10. Glover GW, Fletcher SJ. Assessing the performance of the wisperflow continuos positive airway pressure generator: a bench study. Br J Anaesth 2009;102(6):875-881.

11. Mistraletti G, Giacomini M, Sabbatini G, Pinciroli R, Mantovani ES, Umbrello M, et al. Noninvasive CPAP with face mask: comparison among new air-entrainment masks and the boussignac valve. Respir Care 2013;58(2):305-312.

12. Loius B, Leroux K, Boucherie M, Isabey D, Grillier-Lenor V, Fauroux B, Lofaso F. Pressure stability with CPAP device: a bench evaluation. Sleep Med 2010;11(1):96-99.

13. Kallet RH, Diaz JV. The physiologic effects of noninvasive ventilation. Respir Care 2009;54(1):102-115. 